\title{
Intelligent Controller for UPQC Using Combined Neural Network
}

\author{
Ragavan Saravanan ${ }^{*}$, Subramanian Manoharan ${ }^{2}$ \\ ${ }^{1}$ Christian College of Engineering and Technology Oddachatram, Tamilnadu, India \\ ${ }^{2}$ Thiagarajar College of Engineering Madurai, Tamil Nadu, India \\ Email: *rsharankiruthiga@gmail.com
}

Received 1 March 2016; accepted 7 May 2016; published 11 May 2016

Copyright (C) 2016 by authors and Scientific Research Publishing Inc.

This work is licensed under the Creative Commons Attribution International License (CC BY).

http://creativecommons.org/licenses/by/4.0/

(c) (i) Open Access

\section{Abstract}

The Unified Power Quality Conditioner (UPQC) plays an important role in the constrained delivery of electrical power from the source to an isolated pool of load or from a source to the grid. The proposed system can compensate voltage sag/swell, reactive power compensation and harmonics in the linear and nonlinear loads. In this work, the off line drained data from conventional fuzzy logic controller. A novel control system with a Combined Neural Network (CNN) is used instead of the traditionally four fuzzy logic controllers. The performance of combined neural network controller compared with Proportional Integral (PI) controller and Fuzzy Logic Controller (FLC). The system performance is also verified experimentally.

\section{Keywords}

Unified Power Quality Conditioner (UPQC), Combined Neural Network (CNN) Controller, Fuzzy Logic Controller (FLC), Total Harmonic Distortion (THD)

\section{Introduction}

The UPQC is one of the most researched entities in the world of power electronic control of power systems. Though volumes of papers stream into the literature domain every day, it is very hard to find the real UPQC in service, even in the global electricity distribution scenario. This scenario can be attributed to the fact that the UPQC is hard to understand and it is still harder to handle the piece of equipment from the control system point of view. Many researchers have contributed to the development of the controllers associated with the UPQC. Before proposing this idea, a summary of the existing ideas, as found in the literature, is hinted in this introduction. Ahmet Teke et al. proposed a novel reference signal generation method for the UPQC using the fuzzy logic

\footnotetext{
${ }^{*}$ Corresponding author.
} 
scheme [1]. Ansari et al. proposed a novel algorithm for power angle control (PAC) to improve power quality (PQ) in distribution system [2]. Engin Ozdemir et al. presented a new Synchronous-Reference Frame (SRF) based control method to compensate Power-Quality (PQ) problems through a three-phase four-wire unified PQ conditioner [3]. Raphael J. Millnitz dos Santos et al. discussed dual three-phase topology of UPQC [4]. Srinivas Bhaskar Karanki et al. discussed particle swarm optimization based feedback controller for unified power quality conditioner [5]. Srinivas Bhaskar Karanki et al. proposed reduced dc link voltage rating for modified three-phase four-wire UPQC [6]. Yong Lu et al. demonstrate the space vector modulated transformer less unified power quality conditioner [7]. Q. Xu discussed a single-phase unified power quality conditioner based on the modular multilevel matrix converter [8]. S. K. Khadem et al. demonstrated the integration, and control of unified power quality conditioner in distributed generation based grid connected [9].

In this paper an attempt is made to present a step-by-step development of a simple comprehensive control scheme, at the same time, an effective control scheme for the management of the UPQC with a (CNN) controller, instead of the traditional four controller model. The objectives of this paper are as follows:

1) To maintain a steady voltage profile at the load end by injecting a series voltage in the appropriate phase and magnitude at voltage sag and swell conditions.

2) To eliminate the harmonic content in distribution system during unbalanced and nonlinear load condition.

3) To develop control techniques for overcoming the problems related to dc link voltage deviations during transient conditions.

4) To compensate harmonics currents, unbalanced nonlinear load currents.

\section{Modeling of UPQC}

The UPQC basically has two power electronic converters linked by a common DC link. These two converters engaged in the operation of the constrained power transaction process make use of four controllers that help in meeting out the constraints of power transaction. Shunt converter is a three-leg three-phase Graetz bridge converter with a DC side and a three phase AC side. The three phase AC side is connected across the three phase $\mathrm{AC}$ bus bar at the point of common coupling through a voltage transformer and a series reactor as shown in Figure 1. A pulse width modulation (PWM) generator generating synchronised switching pulses, switch the six switches of the three leg shunt converter. The objectives of the shunt convertor can be achieved by appropriately supplying the switching pulses. The generation of the switching pulses is governed by the three phase reference signal that is produced by the contribution of two controllers. The control objectives of the two controllers influence the generation of the reference signal and this leads to the operation of the convertor meeting out its requirements. There are two controllers associated with the shunt converter.

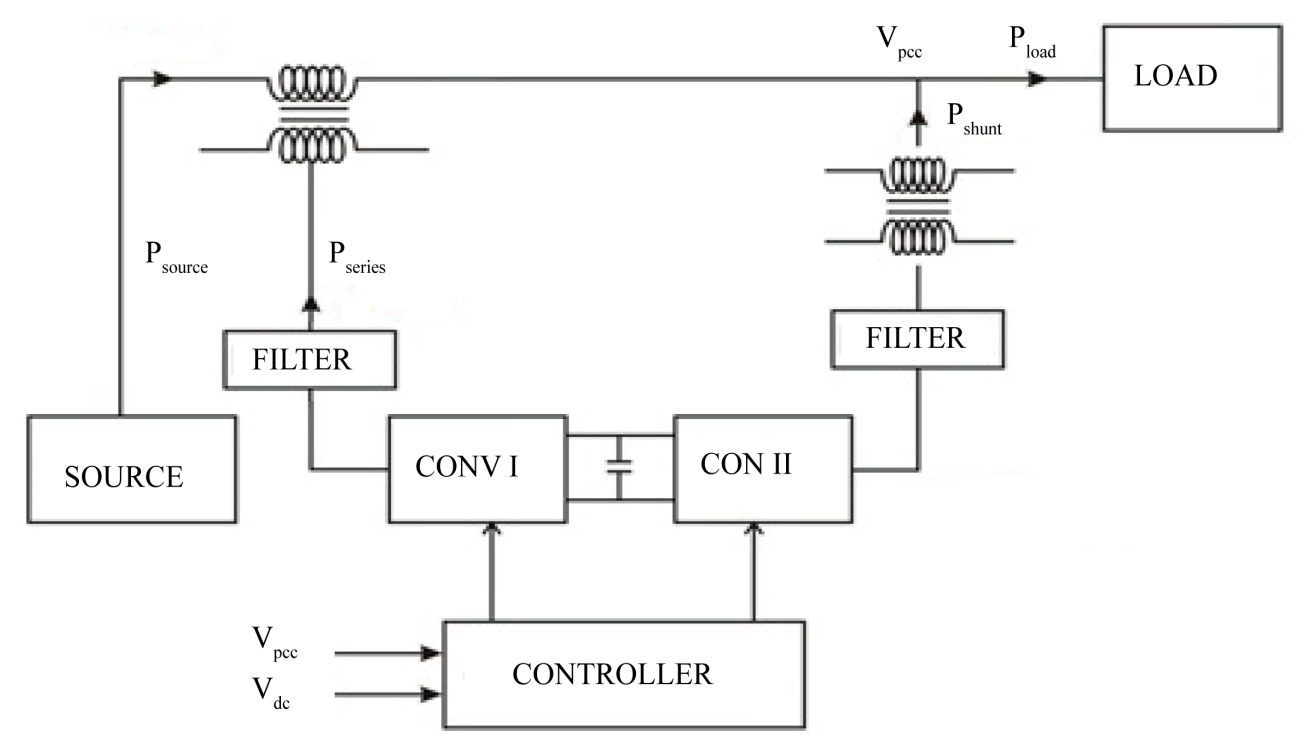

Figure 1. Structure of unified power quality conditioner. 
A block diagram showing the position of the two controllers along with their input and output signals is shown in Figure 2. The first controller is used to make the error between the actual DC link voltage $\left(V_{D C R e f}\right)$ and the desired DC link voltage $\left(V_{D C A C t}\right)$ as zero. The second controller is used to make the error between the actual point of common coupling voltage $\left(V_{\text {pqc Ref }}\right)$ and the desired point of common coupling voltage $\left(V_{\text {pqccAct }}\right)$ as zero. These two are the controlled parameters and the associated manipulated parameters are Theta and amplitude of Modulation Index (MI).

\section{DQ Transformation}

The source side three phase voltages $V_{a}, V_{b}$, and $V_{c}$ are sinusoidal in nature. These quantities are to be converted into equivalent DC quantities and then used in the controllers. The conversion of the three phase sinusoidal voltages denoted as $V_{a b c}$ into, $V_{d}, V_{q}, V_{o}$ and in the rotating frame, is known as DQ transformation or Park transformation. The vector $\left(V_{a}, V_{b}, V_{c}\right)$ can be transformed into another vector $\left(V_{d}, V_{q}, V_{o}\right)$ with the help of a transformation matrix.

$$
\begin{gathered}
{\left[\begin{array}{c}
V_{d} \\
V_{q} \\
V_{0}
\end{array}\right]=\frac{2}{3}\left[\begin{array}{ccc}
\sin \theta & \sin \left(\theta-\frac{2 \pi}{3}\right) & \sin \left(\theta+\frac{2 \pi}{3}\right) \\
\cos \theta & \cos \left(\theta-\frac{2 \pi}{3}\right) & \cos \left(\theta+\frac{2 \pi}{3}\right) \\
\frac{1}{2} & \frac{1}{2} & \frac{1}{2}
\end{array}\right]\left(\begin{array}{l}
V_{a} \\
V_{b} \\
V_{c}
\end{array}\right)} \\
{\left[\begin{array}{l}
V_{a} \\
V_{b} \\
V_{c}
\end{array}\right]=\left[\begin{array}{ccc}
\sin \theta & \cos \theta & 1 \\
\sin \left(\theta-\frac{2 \pi}{3}\right) & \cos \left(\theta-\frac{2 \pi}{3}\right) & 1 \\
\sin \left(\theta+\frac{2 \pi}{3}\right) & \cos \left(\theta+\frac{2 \pi}{3}\right) & 1
\end{array}\right]\left(\begin{array}{l}
V_{d} \\
V_{q} \\
V_{o}
\end{array}\right)}
\end{gathered}
$$

The elements of the vector $\left(V_{a}, V_{b}, V_{c}\right)$ and the elements of the transformation matrix are time varying but the elements of the output vector $\left(V_{d}, V_{q}, V o\right)$ are not time varying.

However any change in the amplitude of either $V_{a}$ or $V_{b}$ or $V_{c}$ is reflected in the elements of the vector $\left(V_{d}, V_{q}\right.$, $\left.V_{o}\right)$.

Park transformation is the conversion of the three phase system of voltages, which are $120^{\circ}$ displaced and varying in a sinusoidal fashion, into another system of three elements which are just constants. However, in the

THETA

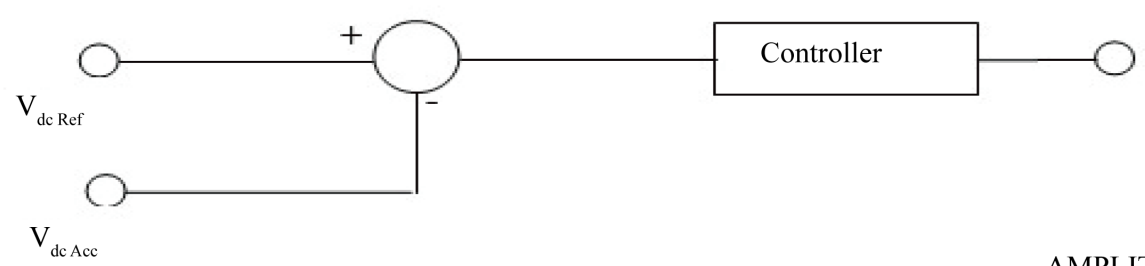

AMPLITUDE

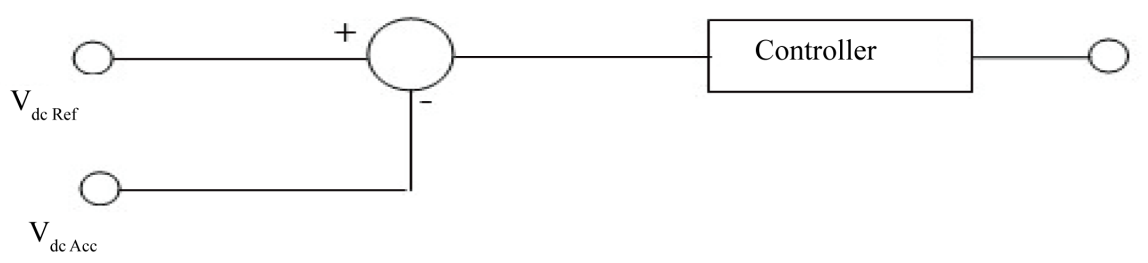

Figure 2. General control scheme. 
transformed system the element $V_{o}$ is zero if the three phase system is balanced. The elements $V_{d}$ and $V_{q}$ are orthogonal in nature that they do not have any influence on each other. In a typical control system both $V_{d}$ and $V_{q}$ can be changed individually without affecting the other.

\section{Combined Neural Networks}

In this work four FLC are designed, two FLCs, each respectively for the series converter and shunt converter. These four FLCs are tuned appropriately for the expected performance. Then these four controllers are replaced by four individual ANN based controllers. Then, the four controllers with two inputs and one output are replaced by a single ANN unit with eight inputs and four outputs. However, if a single ANN is replaced by four ANNs, which results in increasing the speed of operation and better dynamic performance of the system under consideration.

The input and output data required to train the ANNs are the error, error rate and the corresponding output of the FLC, when the FLC controlled model is running environment. The same procedure is simultaneously adopted for collecting the input/output data pertaining to other FLCs. Using the neural network, Four ANNs are formed and each one was trained with the input/output data corresponding to each of the four FLCs.

The UPQC model is then rearranged with the ANNs in the place of the FLCs. The performance of the overall UPQC system, being controlled by the four ANNs, is observed under different loading conditions which could potentially cause disturbances to the power quality. After it is observed that the four ANNs based control scheme worked satisfactorily, they are replaced by a single ANN.

After removing the four ANNs, the UPQC model is now rearranged with the CNN. The inputs and outputs associated with the four ANNs are now routed through the CNN. The performance of the overall UPQC system, being controlled by the CNN is observed under different loading conditions which could potentially cause disturbances to the power quality.

The synaptic weights are randomly initialised at the first time formation of an ANN but during the training phase, the synaptic weights undergo changes according to the learning rule. Finally, as the training is over, each synaptic weight reaches its final value. During the test phase or during the period, the ANN is put under service to mimic a function. Even as the inputs are applied, the synaptic weights do not change; they just work together with the neurons to give the output. A CNN is feed forwards back propagation type and its basic form has an input layer, a hidden layer and an output layer. There may be more number of hidden layers than one. Let us consider the case of CNNs having only one hidden layer. The style adopted in the CNN model as shown in Figure 3. Actually, as a result of combination of the ANNs, the resultant ANN has now more number of inputs and outputs. However, the number of neurons in the hidden layer remains the same. Thus, all the neural networks combined to form the ANN, have to share the common hidden layer neurons. As an example of demonstrate as how the ANNs are combined in this work, the following example may be considered. Going by an example, consider the following two nonlinear equations in "time".

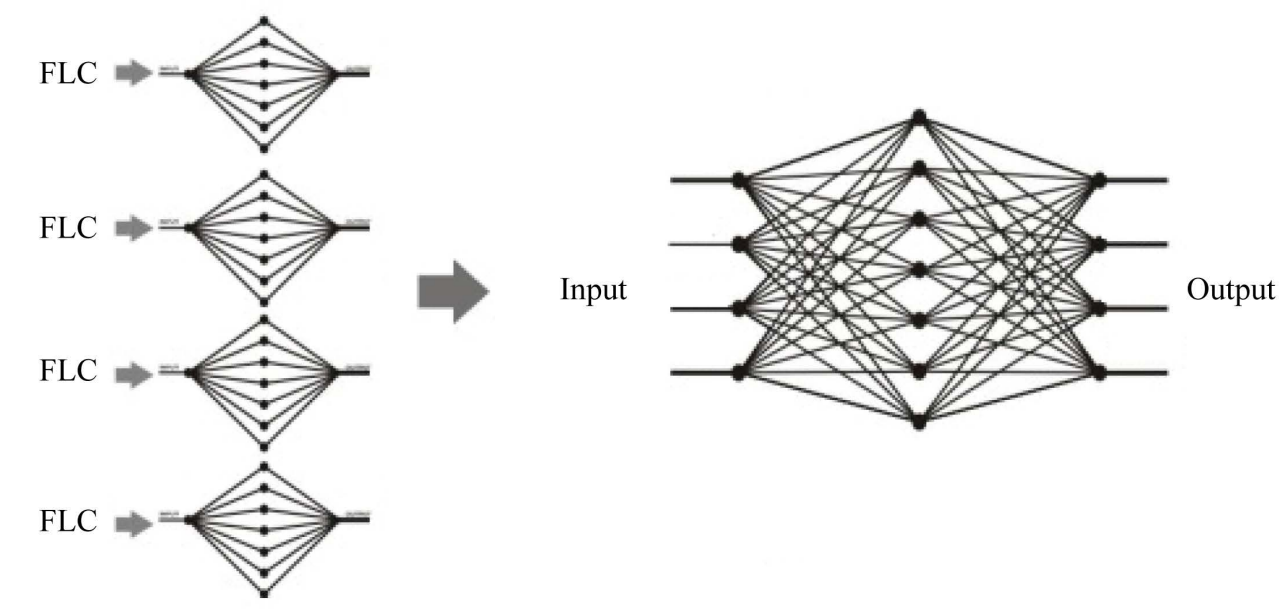

Figure 3. CNN model. 


$$
\begin{aligned}
& Y_{1}=5 t^{3}+2 t^{2}+3 t \\
& Y_{2}=2 t^{3}+7 t^{2}+5 t
\end{aligned}
$$

Consider two independent ANNs which are trained respectively with the input/output data set, for the range of time, between 0 and 1, in steps of 0.01 , as dictated by each of the two Equations (3) and (4). Upon creating and training two ANNs in the MATLAB/SIMULINK environment, two test models are constructed to test the performance of the two ANNs. A third ANN is then created with two inputs and two outputs. This is the combined model. The output vectors of model 1 and 2 are now used as the output for the third model. The third ANN was then trained. The performance of the combined model is as good as the performance of the individual ANN. For the context of the paper, it is enough to observe that the combined ANN performs as good as the individual ANN.

\section{Simulation Results}

In this article, to demonstrate the proposed control strategy of CNN model described in Figure 4. The performance of the novel CNN based controller for the UPQC can be appreciated by comparing the results of the multiple controllers. Under unbalanced condition Figure 5(a) shows the source voltage distotded in sag and swell condition. The compensation of voltage sag and swell condition using PI controller, Fuzzy logic controller, ANN controller and CNN controller depicted in Figure 5(b). From Figure 5(b) after compensation of voltage swell condition the perunit values PI, FLC and ANN controllers are 1.083, 1.038, 1.102 respectively. But in CNN controller after compensation of voltage swell condition the perunit value is 0.983 (nearest to unity), similarly after compensation of voltage sag condition the per unit value of CNN controller nearest to unity (0.994). The load voltage is maintained at the constant value, irrespective of the voltage sag and swell in the source voltage magnitude. In this case, the voltage sag and swell can be analyzed by creating unbalanced load on the network system. The time duration of the voltage sag is $0.5 \mathrm{sec}-0.1 \mathrm{sec}$ and voltage swell from its duration between 0.15 $0.2 \mathrm{sec}$. The supply voltages are unbalanced sinusoidals with the magnitudes below the 1 per unit. The series compensator injecting the voltage,the load side maintains balanced sinusoidal voltage. The load voltage maintain the nominal value of 1 per unit. The UPQC can compensate voltage of sag and swell conditions under PI controller, Fuzzy logic controller, ANN controller and CNN controller depicted in Figure 5(b).

Performance analysis of PI, FLC and CNN controller are shown in Table 1. From the results, CNN controller

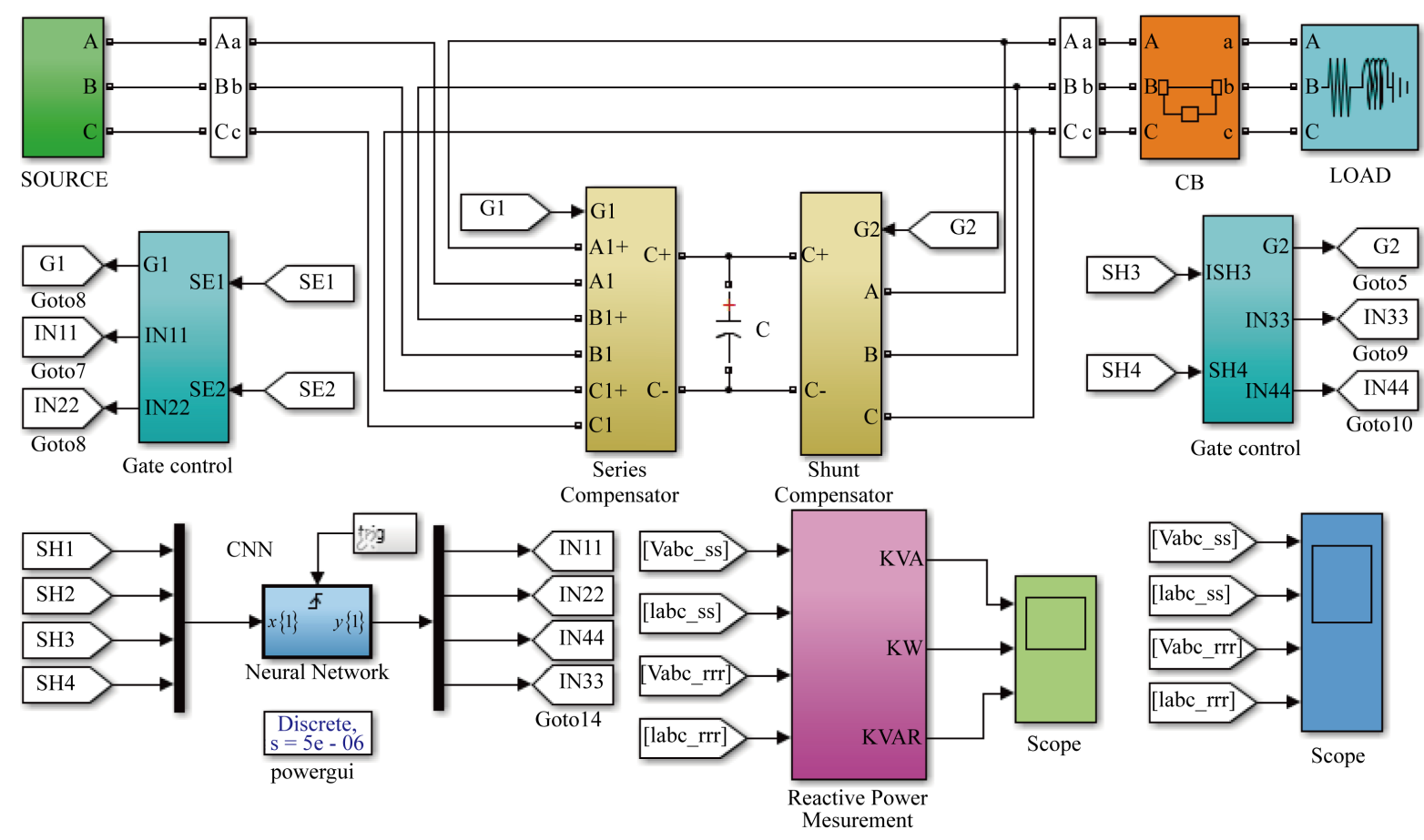

Figure 4. Simulink model of proposed CNN system. 


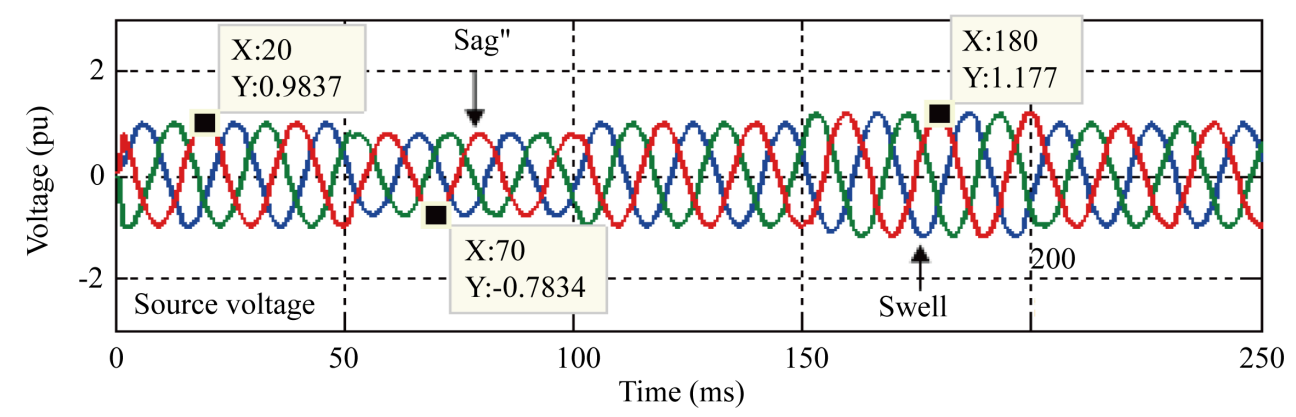

(a)

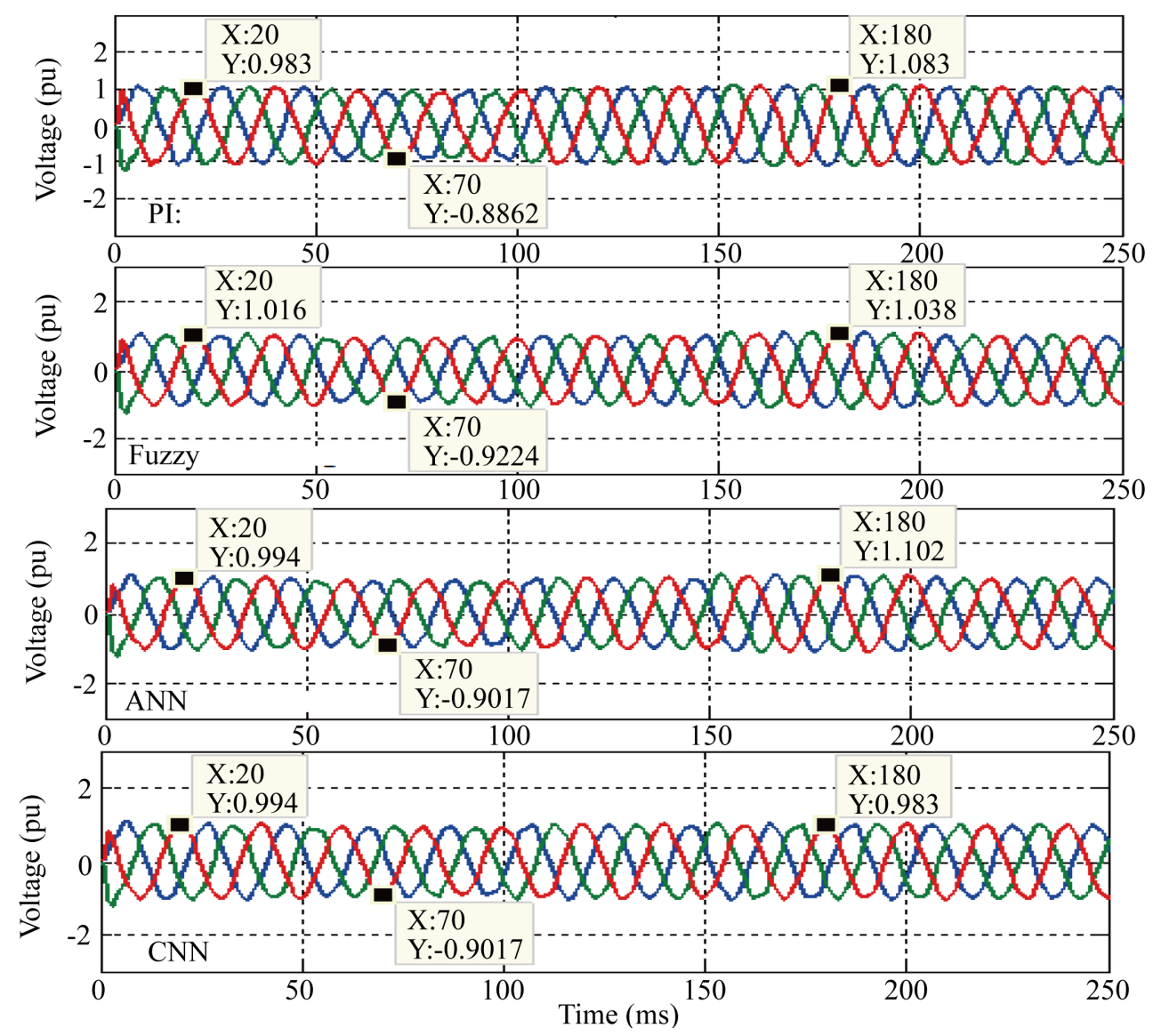

(b)

Figure 5. (a) Source voltage; (b) Compensation of voltage sag and swell.

Table 1. Performance analysis of PI, FLC and CNN controller.

\begin{tabular}{ccccccc}
\hline & \multicolumn{2}{c}{ PI controller } & \multicolumn{2}{c}{ FLC } & \multicolumn{2}{c}{ CNN Controller } \\
\cline { 2 - 7 } Quantity/R phase & THD\% & Magnitude & THD\% & Magnitude & THD\% & Magnitude \\
\hline Source voltage & 3.82 & 0.983 & 3.12 & 0.983 & 2.66 & 0.983 \\
Load voltage & 2.52 & 0.983 & 2.23 & 1.01 & 1.90 & 0.994 \\
Source current & 3.81 & 0.965 & 2.86 & 0.949 & 2.46 & 0.956 \\
Load current & 2.53 & 0.968 & 1.92 & 0.965 & 1.21 & 0.943 \\
\hline
\end{tabular}


THDs are maintained within permissible limits. The source voltage under distorted condition from $0.5 \mathrm{sec}-0.1$ sec undergoes sag condition. The source voltage with sag/swell before compensation has THDs of $2.66 \%$ in $\mathrm{R}$ phase. The load voltage with sag/swell after compensation has THDs $1.90 \%$ in R phase respectively. An unbalanced created in load condition, the shunt compensator forces the load current to be sinusoidal in nature. The source current before compensation have THDs of $2.46 \%$. The source current after compensation have THDs of $1.21 \%$. Hence in different controllers operation, from Table 1, it is clear that CNN controller gives better performance in terms of reduced THDs in voltage and current after compensation. The THD within the limit specified in the IEEE 519-1922. From Figure 6(a) and Figure 6(b), shows the load voltage is maintained constant irrespective of voltage sag and swell condition. The Figure 6(a) shows the source side active power and reactive power during sag and swell condition with a load. The Figure 6(b) shows the load side compensated output results of active power and reactive power at the simulation time of 0.15 to $0.20 \mathrm{sec}$.

It is observed from the Table 2, that the THD of the source current is $2.68 \%$ for single ANN controller while it is $2.46 \%$ for CNN. Similarly, the THD for load current is $1.69 \%$ for single ANN controller while it is $1.21 \%$ for CNN controller. The THDs of source voltage, load voltage, source current and load current with CNN controller is shown in Figure 7. The Total harmonic distortion (THD) of the source voltage with CNN controller is $2.66 \%$ and load voltage is $1.90 \%$. The Total harmonic distortion (THD) of the source voltage with ANN controller is $2.96 \%$ and load voltage is $2.16 \%$. The Total harmonic distortion (THD) of the source current with CNN controller is $2.46 \%$ and load current is $1.21 \%$. The Total harmonic distortion (THD) of the source current before compensation with ANN controller is $2.68 \%$ after compensation the load current is reduced $1.69 \%$.it is observed from the simulation results, the performance of CNN controller gives harmonics elimination better than ANN controller and conventional controllers. The proposed CNN shows encouraging improvement in THD compared to the announced work performed with Vadirajacharya G. Kinhal et al. [10].

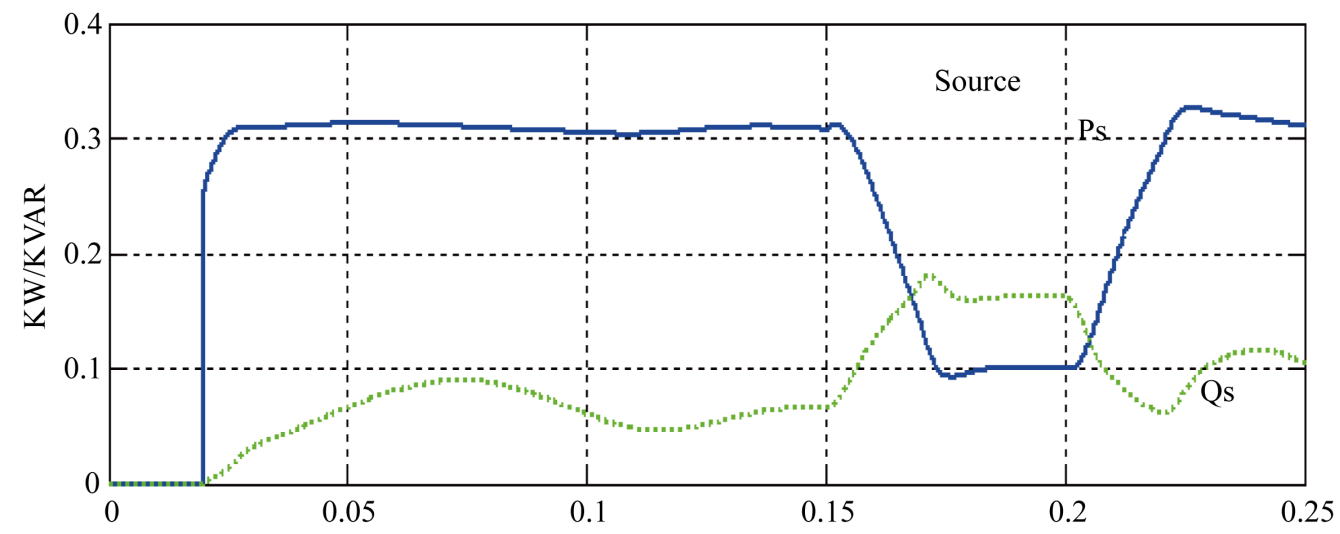

(a)

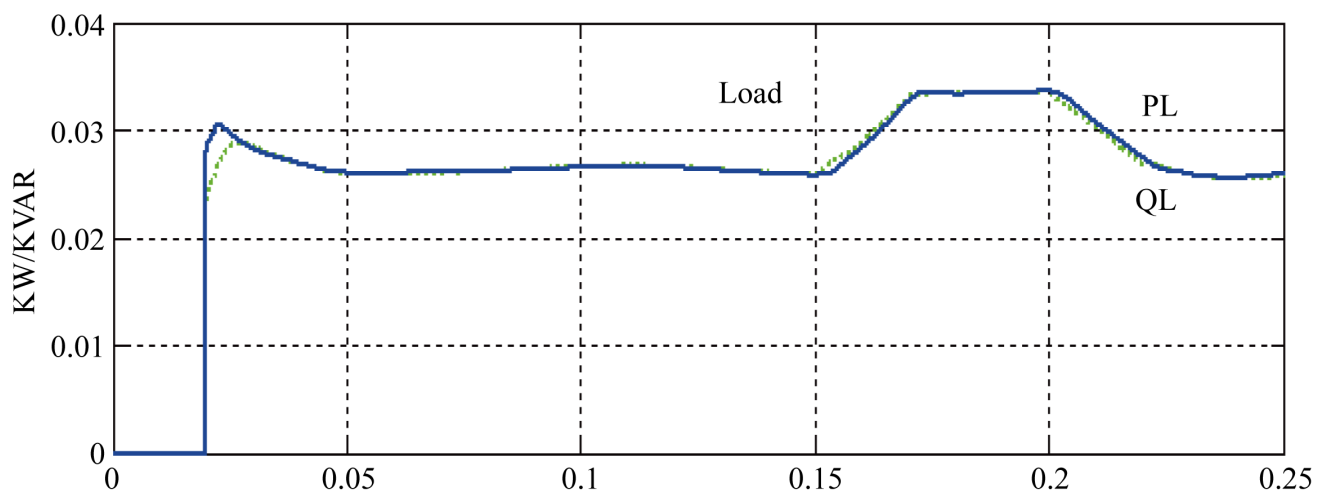

(b)

Figure 6. Real and reactive power on source and load side. (a) Source side (Ps: Source side active power, Qs: Source side reactive power); (b) Load side $\left(\mathrm{P}_{\mathrm{L}}\right.$ : Load side active power, $\mathrm{Q}_{\mathrm{L}}$ : Load side reactive power). 

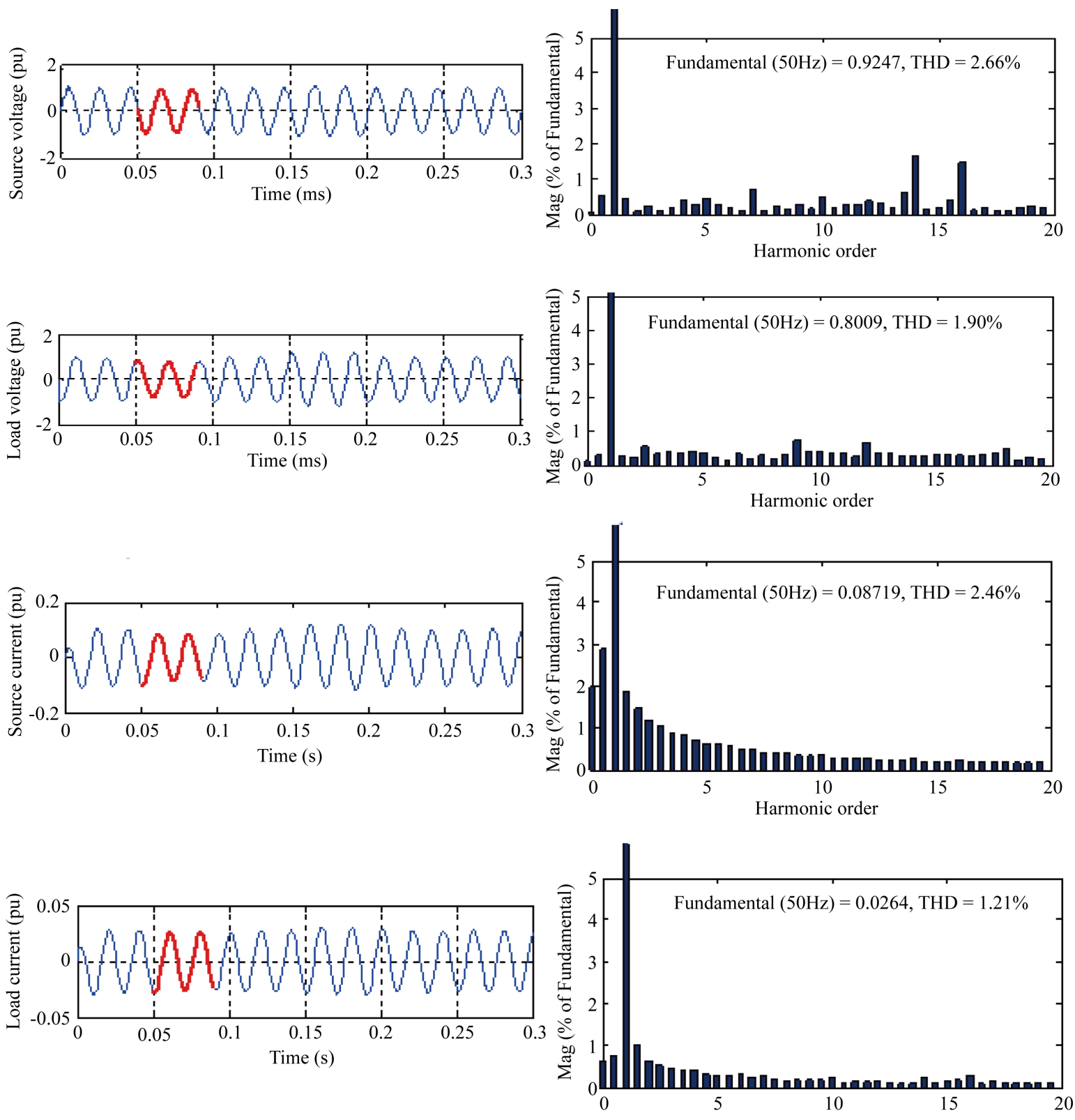

Harmonic order

Figure 7. THD level of "R" phase for CNN controller.

Table 2. Performance analysis of ANN and CNN controller.

\begin{tabular}{ccccc}
\hline \multirow{2}{*}{ Quantity/R phase } & \multicolumn{2}{c}{ ANN Controller } & \multicolumn{2}{c}{ CNN Controller } \\
\cline { 2 - 4 } & THD\% & Magnitude & THD\% & Magnitude \\
\hline Source voltage/sag & 2.96 & 0.983 & 2.66 & 0.994 \\
Load voltage & 2.16 & 0.994 & 1.90 & 0.994 \\
Source voltage/swell & 2.96 & 1.177 & 2.66 & 1.17 \\
Load voltage & 2.16 & 0.994 & 1.90 & 0.983 \\
Source current & 2.68 & 0.968 & 2.46 & 0.956 \\
Load current & 1.69 & 0.976 & 1.21 & 0.943 \\
\hline
\end{tabular}




\section{Experimental Results}

The performance of proposed concept is validated through experimental results. The hardware laboratory setup is shown in Figure 8. The source voltage, load voltage, source current and load current for single phase can be seen in hardware results. The structure of the CNN, realized in simulation, can be easily implemented in KEIL C and can be embedded in the microcontroller. The sigmoidal functions, used by the CNN can be implemented by the programming segment shown below. The segment of the program containing the sigmoidal function can be kept as a $\mathrm{C}$ function and can be called repeatedly by the CNN main program. The synaptic weights of the MATLAB simulated CNN units are constants and in the keil implementation the synaptic weights are implemented as floating point constants. The trained CNN controller is simulated using microcontroller unit. To the sudden variation in load creates the sag and swell conditions.

Figure 9 shows the experimental results during voltage sag condition. Figure 9(a) shows the unbalanced source voltage and corresponding THDs which are found to be $2.79 \%$. Figure 9(b) shows the compensated load voltage and corresponding THDs which are found to be $1.98 \%$. The load voltage maintains constant value.

The experimental results during voltage swell condition are shown in Figure 10. The increased source voltage and corresponding THDs which are found to be $2.79 \%$ is shown in Figure 10(a). The compensated load voltage and corresponding THDs which are found to be $1.98 \%$ is shown in Figure 10(b). The series converter is used to injecting voltage, which are compensated load voltage.

An unbalanced load condition, the source currents (sag) is distorted and unbalanced condition is shown in Figure 11(a) and corresponding THDs which are found to be $2.52 \%$. The experimental results of current compensation are shown in Figure 11(b) and measured THD value of load current is 1.29\%.

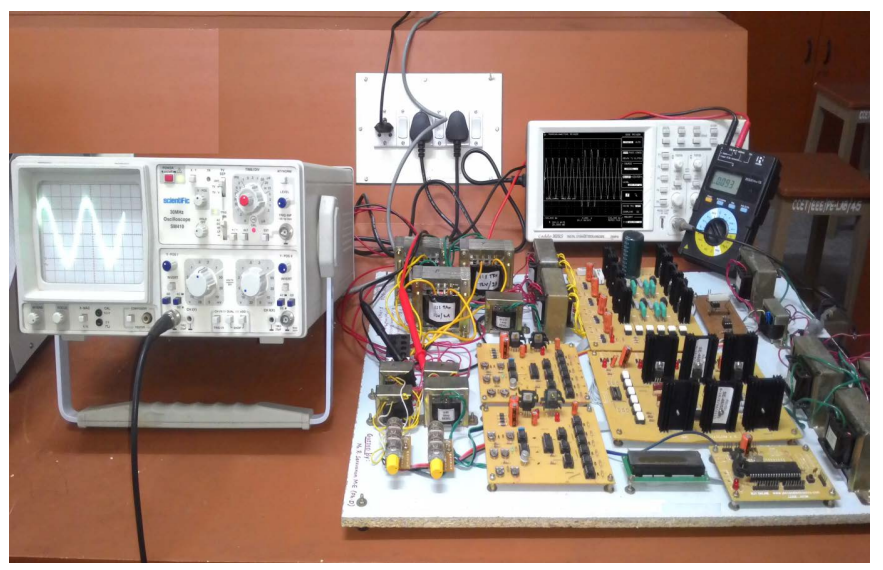

Figure 8. Hardware setup.

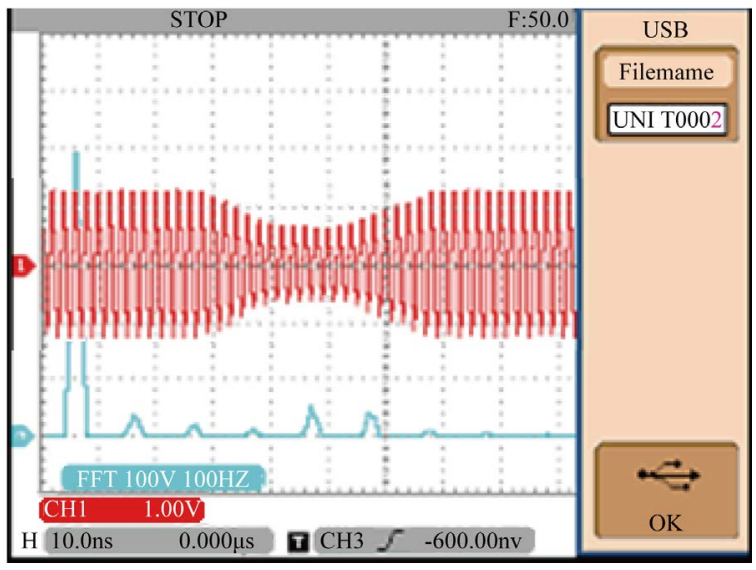

(a)

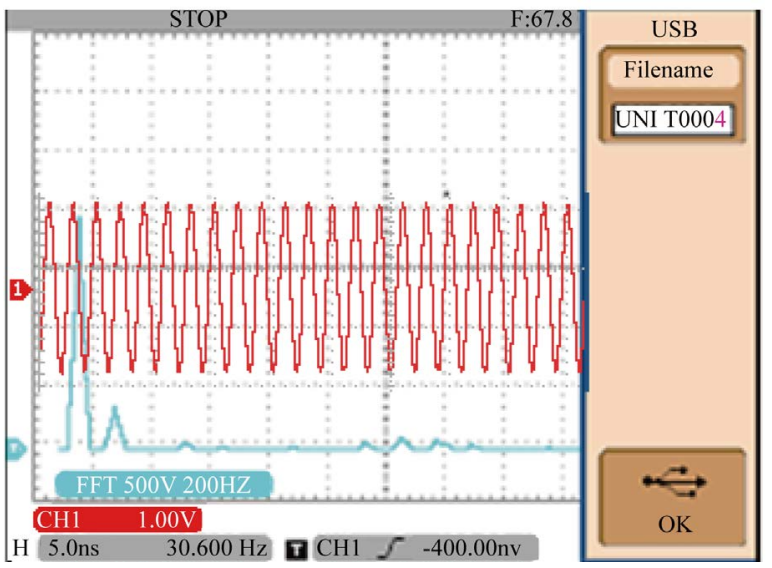

(b)

Figure 9. Voltage sag and harmonics. 
An unbalanced load condition, the source currents (swell) is distorted and unbalanced condition is shown in Figure 12(a) and corresponding THD which are found to be $2.52 \%$. The experimental results of current compensation are shown in Figure 12(b) and measured THD value of load current is 1.29\%, where the scale of $1 \mathrm{~V}$ is equal to $1 \mathrm{~A}$.

It can be seen that source current is non-sinusoidal and the wave shape of the compensating load current is sinusoidal in nature, due to the action of shunt converter, the load currents balanced and sinusoidal. Hence in CNN controller gives the harmonic elimination and voltage compensation. The Experimental results in terms of THD levels of voltage and current after compensation are shown in Table 3. The THD level of the load voltage and load current after compensation are $1.98 \%$ and $1.29 \%$ respectively.

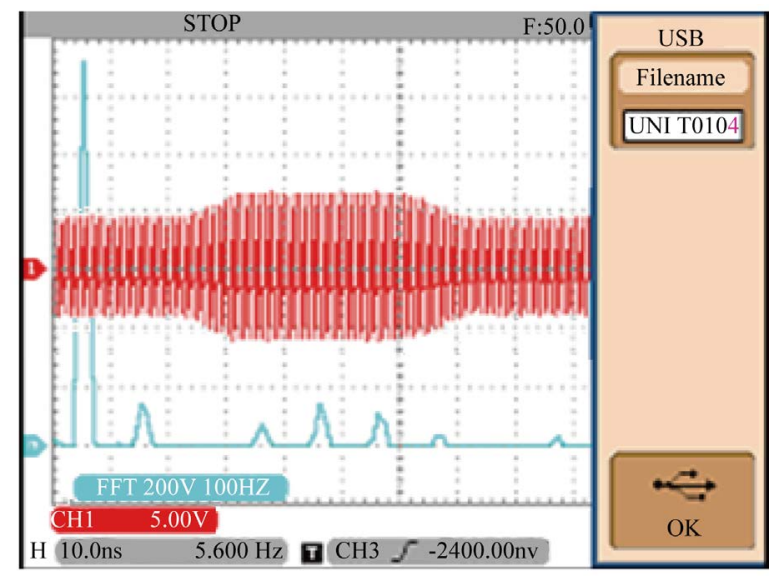

(a)

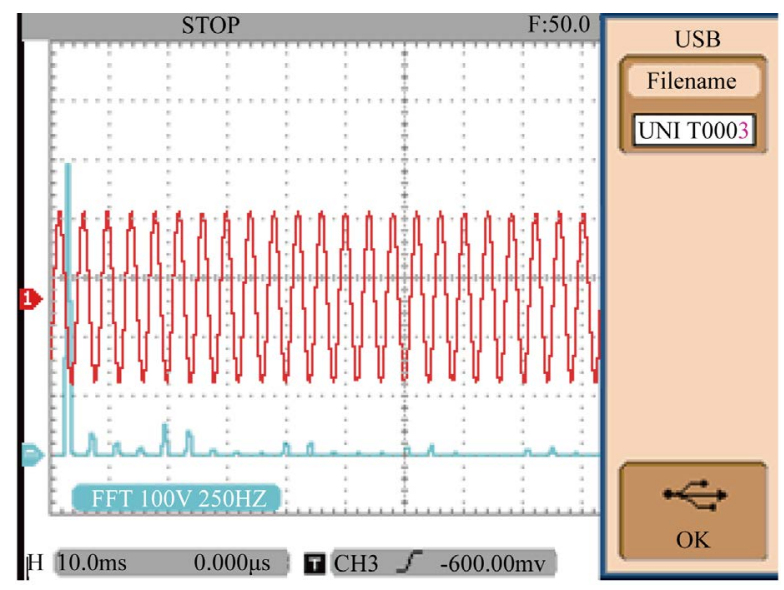

(b)

Figure 10. Voltage swell and harmonics. (a) Source voltage phase "R"; (b) Load voltage phase "R".

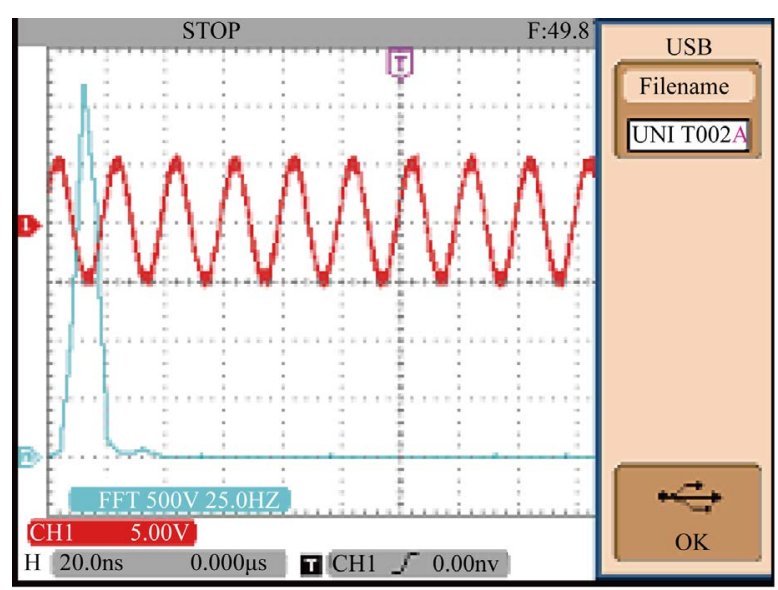

(a)

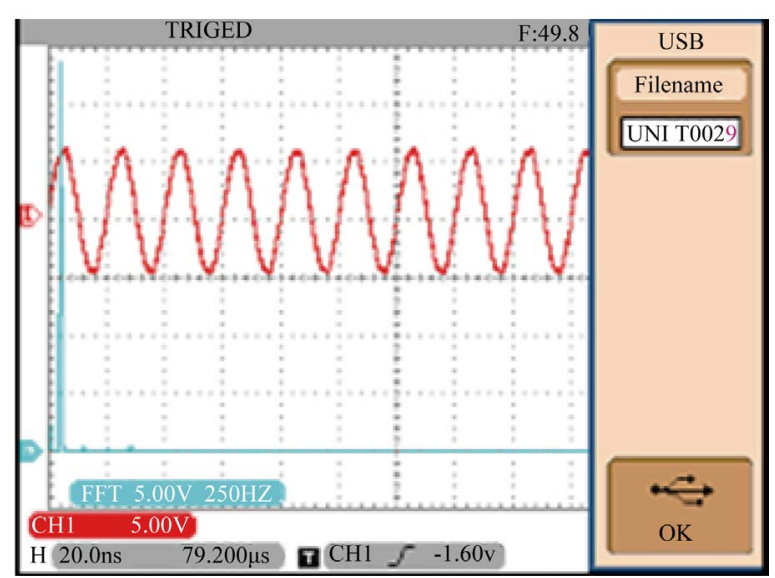

(b)

Figure 11. Sag current and harmonics. (a) Source current phase "R"; (b) Load current phase "R".

Table 3. Experimental results.

\begin{tabular}{cc}
\hline Quantity/R phase & THD\% \\
\hline Source voltage & 2.79 \\
Load voltage & 1.98 \\
Source current & 2.52 \\
Load current & 1.29 \\
\hline
\end{tabular}




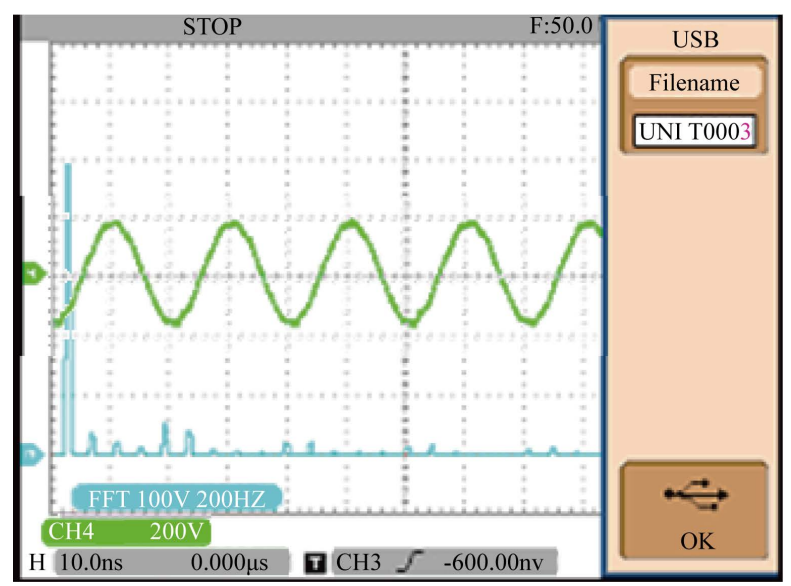

(a)

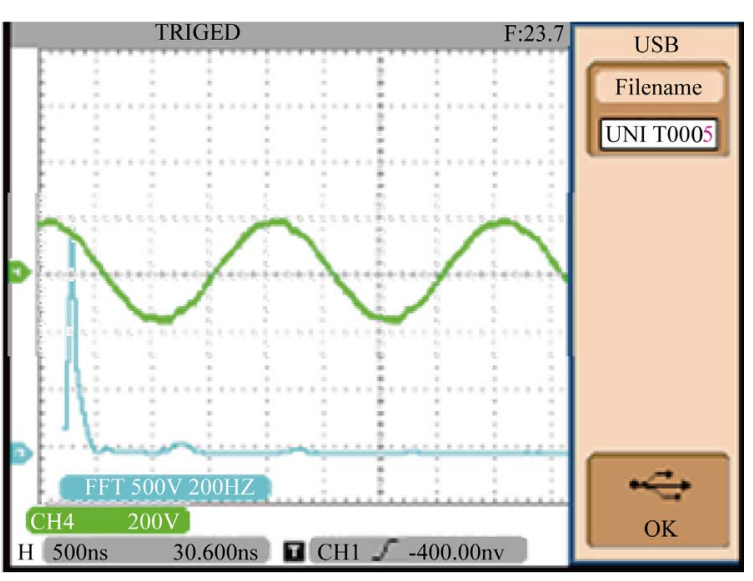

(b)

Figure 12. Swell current and harmonic. (a) Swell source current phase "R”; (b) Swell load current phase "R”.

\section{Conclusion}

A new methodology is proposed to compensate voltage sag, voltage swell and reactive power compensation. The artificial intelligence based CNN controller has been developed. The proposed system can improve the power quality at the distribution systems. The simulation model and hardware prototype model delineate in this paper. It can be implemented for higher power rating circuits. The acceptable results for the proposed system summarized as follows. Moreover, proposed control scheme is in steady state and transient response. A detailed comparison is also verified between conventional controllers. The proposed controller provides better performance with conventional controllers. The current unbalance, current harmonics, and load reactive power of nonlinear loads are compensated. The simulation results are validated experimentally.

\section{References}

[1] Teke, A., Saribulut, L. and Tumay, M. (2011) A Novel Reference Signal Generation Method for Power-Quality Improvement of Unified Power-Quality Conditioner. IEEE Transactions on Power Delivery, 26, 2205-2214. http://dx.doi.org/10.1109/TPWRD.2011.2141154

[2] Ansari, A.Q., Singh, R. and Hasan, M. (2015) Algorithm for Power Angle Control to Improve Power Quality Distribution System Using Unified Power Quality Conditioner. IET Generation, Transmission and Distribution, 9, 1439-1447. http://dx.doi.org/10.1049/iet-gtd.2014.0734

[3] Kesler, M. and Ozdemir, E. (2011) Synchronous-Reference-Frame-Based Control Method for UPQC under Unbalanced and Distorted Load Conditions. IEEE Transactions on Industrial Electronics, 58, 3967-3975.

[4] dos Santos, R.J.M., da Cunha, J.C. and Mezaroba, M. (2014) A Simplified Control Technique for a Dual Unified Power Quality Conditioner. IEEE Transactions on Industrial Electronics, 61, 5851-5860.

[5] Karanki, S.B. and Mishra, M.K. (2010) Particle Swarm Optimization-Based Feedback Controller for Unified PowerQuality Conditioner. IEEE Transactions on Power Delivery, 25, 2814-2824. http://dx.doi.org/10.1109/TPWRD.2010.2047873

[6] Karanki, S.B., Geddada, N., Mishra, M.K. and Kumar, B.K. (2013) A Modified Three-Phase Four-Wire UPQC Topology with Reduced DC-Link Voltage Rating. IEEE Transactions on Industrial Electronics, 60, 3555-3566.

[7] Lu, Y., Xiao, G.C., Wang, X.F., Blaabjerg, F. and Lu, D.P. (2016) Control Strategy for Single-Phase Transformer Less Three-Leg Unified Power Quality Conditioner Based on Space Vector Modulation. IEEE Transactions on Power Electronics, 31, 2840-2849. http://dx.doi.org/10.1109/TPEL.2015.2449781

[8] Xu, Q.M., Ma, F.J., Luo, A., He, Z.X. and Xiao, H.G. (2016) Analysis and Control of M3C based UPQC for Power Quality Improvementin Medium/High Voltage Power Grid. IEEE Transactions on Power Electronics, 26, 1. http://dx.doi.org/10.1109/TPEL.2016.2520586

[9] Khadem, S.K., Basu, M. and Conlon, M.F. (2015) Intelligent Islanding and Seamless Reconnection Technique for Microgrid with UPQC. IEEE Journal of Emerging and Selected Topics in Power Electronics, 3, 483-492. http://dx.doi.org/10.1109/JESTPE.2014.2326983 
[10] Kinhal, V.G., Agarwal, P. and Gupta, H.Q. (2011) Performance Investigation of Neural-Network-Based Unified Power-Quality Conditioner. IEEE Transactions on Power Delivery, 26, 431-437.

http://dx.doi.org/10.1109/TPWRD.2010.2050706 